\title{
AVALIAÇÃO DA ÁGUA ATRAVÉS DE PARÂMETROS MICROBIOLÓGICOS E FÍSICO-QUÍMICOS EM ÁREAS POPULACIONAIS DO ARROIO LUIZ RAU, AFLUENTE DO RIO DOS SINOS, MUNICÍPIO DE NOVO HAMBURGO, RS
}

\author{
WATER ASSESSMENT THROUGH MICROBIOLOGICAL AND PHYSICO-CHEMICAL PARAMETERS IN \\ POPULATION AREAS OF LUIZ RAU STREAM, AFFLUENT OF RIO DOS SINOS, \\ MUNICIPALITY OF NOVO HAMBURGO, RS
}

\author{
Tatiana Moraes da Silva Heck'; Larissa Ferreira de Jesus² \\ Natália Tomasetto de Deus ${ }^{3}$; Rafael Linden 4 \\ Daniela Montanari Migliavacca Osório5; Rodrigo Staggemeier6
}

\author{
Recebido em: 20 de fevereiro de 2017 \\ Aprovado em: 09 de maio de 2017 \\ Sistema de Avaliação: Double Blind Review \\ RCO | a. 9 | v. 2 | p. 105-117 | jul./dez. 2017
}

\section{RESUMO}

O Arroio Luiz Rau é um dos principais arroios do município de Novo Hamburgo, Rio Grande do Sul (RS) com sua foz no trecho inferior da Bacia Hidrográfica do Rio dos Sinos. O aumento populacional nos grandes centros urbanos gera problemas sanitários devido à falta de saneamento, afetando o ecossistema hídrico. A fim de analisar os poluentes fecais e físico-químicos do presente arroio, afluente do Rio dos Sinos, foi avaliada a qualidade da água do córrego através da pesquisa de adenovírus humano gastroentérico (HAdV-F), adenovírus respiratório (HAdV-C), adenovírus animal, parâmetros microbiológicos e físico-químicos, bem como avaliação da cafeína, marcador de contaminação antrópica. Dois pontos demarcados por concentração populacional no município de Novo Hamburgo foram alvos do presente estudo, contribuindo na caracterização do impacto antrópico e ambiental até o Rio dos Sinos. Índices de contaminação foram observados nos dois pontos analisados, sendo o ponto 2 com os maiores índices de contaminação fecal e ambiental, acompanhado de análises físico-químicas. A análise de cafeína revelou que este é um bom marcador de contaminação antrópica, entretanto apontou índices maiores no Ponto 1. O Arroio Luiz Rau revelou uma forte contaminação de origem antrópica, colaborando na disseminação de microrganismos, os quais afetam a qualidade das águas do Rio dos Sinos, utilizado para abastecimento público na região.

Palavras-chave: Qualidade da água. Esgotamento Sanitário. Monitoramento ambiental. Microrganismos. Saúde Pública.

\section{ABSTRACT}

Luiz Rau stream is one of the main streams of the municipality of Novo Hamburgo, Rio Grande do Sul (RS) with its mouth in the lower stretch of the Rio dos Sinos Watershed. The increase in population in

\footnotetext{
${ }^{1}$ Mestre em Qualidade Ambiental pela Universidade Feevale (Novo Hamburgo/Brasil). E-mail: tatianaheck@terra.com.br.

${ }^{2}$ Mestre em Qualidade Ambiental pela Universidade Feevale (Novo Hamburgo/Brasil). E-mail: larissafj@ gmail.com.

${ }^{3}$ Mestre em Qualidade Ambiental pela Universidade Feevale (Novo Hamburgo/Brasil). Professora da Faculdade Metropolitana do Planalto Norte (Canoinhas/Brasil). E-mail: nataliatd.adv@ gmail.com.

${ }^{4}$ Doutor em Biologia Celular e Molecular pela Pontifícia Universidade Católica do Rio Grande do Sul (Porto Alegre/Brasil). Professor na Universidade Feevale (Novo Hamburgo/Brasil). E-mail: rafael.linden@ feevale.br.

${ }^{5}$ Doutora em Ecologia pela Universidade Federal do Rio Grande do Sul (Porto Alegre/Brasil). Professora na Universidade Feevale (Novo Hamburgo/Brasil). E-mail: danielaosorio@ feevale.br.

${ }^{6}$ Doutor em Qualidade Ambiental pela Universidade Feevale (Novo Hamburgo/Brasil). Professor na Universidade Feevale (Novo Hamburgo/Brasil). E-mail: rodrigostaggemeier@ feevale.br.
} 
large urban centers causes sanitary problems due to lack of sanitation, affecting the water ecosystem. In order to analyze fecal and physicochemical pollutants of the present stream, affluent of the Rio dos Sinos, the water quality of the stream was evaluated through the research of gastroenterical human adenovirus (HAdV-F), respiratory adenovirus (HAdV-C), animal adenovirus, microbiological and physicochemical parameters, as well as evaluation of caffeine, a marker of anthropogenic contamination. Two points demarcated by population concentration in the municipality of Novo Hamburgo were the targets of the present study, contributing to the characterization of the anthropic and environmental impact up to the Rio dos Sinos. Contamination indices were observed in the two analyzed points, being the point 2 with the highest indexes of fecal and environmental contamination, accompanied by physicochemical analyzes. The analysis of caffeine revealed that this is a good marker of anthropic contamination, however it indicated higher indexes in Point 1. Luiz Rau stream revealed a strong contamination of anthropic origin, collaborating in the dissemination of microorganisms, which affect the water quality of the Rio dos Sinos, used for public supply in the region.

Keywords: Water Quality. Sewage System. Environmental monitoring. Microorganisms. Public Health.

\section{INTRODUÇÃO}

O crescimento populacional e o aumento de residências sem planejamento e estrutura adequada geram problemas de ordem sanitária devido à falta de saneamento, o que afeta principalmente o ecossistema hídrico. As maiores fontes de contaminação hídrica nos centros populacionais são decorrentes de despejos de efluentes industriais, curtumes e esgoto doméstico não tratado (STEFFENS et al., 2015). Por sua vez, o município de Novo Hamburgo produz grande carga orgânica através de efluentes domésticos que acabam no curso hídrico de arroios e por fim são lançados no Rio dos Sinos, o qual é fonte de abastecimento público, podendo atingir pontos de captação de água (STAGGEMEIER, 2016).

O Arroio Luiz Rau é um dos principais arroios do município de Novo Hamburgo, Rio Grande do Sul (RS) (Figura 1), sua nascente localiza-se na divisa com o município de Estância Velha, e sua foz no Rio dos Sinos. O município concentra uma população de 238.940 habitantes e a densidade demográfica é de 1.067,55 hab/Km² (PREFEITURA DE NOVO HAMBURGO, 2015; IBGE, 2010). Devido a sua grande extensão de $13 \mathrm{~km}$, o arroio situado na porção baixa da Bacia Hidrográfica do Rio dos Sinos (BHRS) é demarcado por maior concentração populacional urbana e recebe efluentes como esgoto doméstico e industrial, prejudicando a qualidade da água e do solo (ÁVILA, 2011).

Figura 1 - Localização geográfica do Arroio Luiz Rau e seus principais afluentes, Novo Hamburgo, RS



Fonte: http://www.comusa.rs.gov.br/index.php/meioAmbiente/pesquisa. Adaptado por Tatiana Heck 
Segundo Rodrigues et al. (2015) apenas 4,5\% do esgoto da BHRS é tratado e frequentemente o esgoto doméstico e resíduos rurais são depositados no ambiente podendo contaminar mananciais de captação de água com microrganismos de origem fecal e alterar as condições de seu consumo em regiões que não possuem saneamento básico ou de sistema precário, e segundo Blume et al. (2010), há um significativo déficit na qualidade da água do Rio dos Sinos, deslumbrando um cenário preocupante para esta região. Em outro estudo, Robaina et al. (2002) relataram elevadas concentrações de metais em seu curso hídrico, assim o Sinos tornou-se foco de pesquisas uma vez que possui uma baixa qualidade hídrica, indicando uma grande carga orgânica associada à elevada densidade populacional como uma das principais causas deste resultado (ANA, 2013).

O saneamento básico é de extrema importância no controle de disseminação de microrganismos como vírus e bactérias para preservação dos recursos hídricos (PRADO; MIAGOSTOVISH, 2014), bem como garantir parâmetros físico-químicos para uma boa qualidade da água de consumo humano. Outro marcador com potencial de identificação antrópica é a análise da cafeína, excreta através de fezes e urina, é capaz de identificar de forma precisa a contaminação humana (LINDEN et al., 2015).

As realizações de estudos são importantes em afluentes do Rio dos Sinos, dentre eles, o Arroio Luiz Rau considerado um dos principais receptores de poluição doméstica do município. A identificação da fonte de microrganismos de origem fecal humana e animal, como vírus e bactérias, contaminantes físico-químicos e marcador humano de excreção metabólica como a cafeína tornam-se essenciais, uma vez que a presença de contaminantes demonstra um problema oriundo do lançamento de esgotos sem tratamento adequado, que poderão atingir outros cursos de águas (VIEIRA et al., 2012). Além disso, demonstrar a presença de microrganismos patogênicos em recursos hídricos reflete diretamente na saúde humana, dimensionar quais patógenos à população está exposta e a degradação do ambiente pela ação humana enfatiza a necessidade de tomada de decisões de gestores governamentais.

Vírus entéricos compreendem todos os grupos de vírus que estão presentes no trato gastrintestinal de humanos e animais, largamente disseminados através de esgoto não tratado. Transmitidos de forma fecal-oral, por contato com partículas de água e solo contaminado. Dentre eles, podemos destacar o Adenovírus Humano (HAdV) e Adenovírus (AdV) animal, os mais comumente encontrados no ambiente (WYN-JONES et al., 2011; STAGGEMEIER et al., 2015).

De acordo com o Comitê Internacional de Taxonomia Viral (ICTV) os HAdV pertencem a família Adenoviridae, e ao gênero Mastadenovirus, acometem mamíferos e apresentam mais de 67 sorotipos humanos divididos em 7 subgrupos de A a G, em destaque, a espécie F dos tipos 40 e 41 (HAdVF-40 e HAdVF-41) que são específicos gastroentéricos bem como o HAdV da espécie $\mathrm{C}$ dos tipos 2 e 5 (HAdVC-2 e HAdVC-5) que são respiratórios (MATSUSHIMA et al., 2013). Possuem genoma de DNA fita dupla, são vírus não envelopados, característica as quais os tornam mais resistentes aos processos de cloração (MEHNERT et al., 2001; VELLINGA et al., 2005). Causadores de gastroenterites, infecções respiratórias, conjuntivites e até mesmo cardiopatias, acometem menores de 5 anos e adultos imunocomprometidos (DASHTI et al., 2016).

As doenças diarreicas virais ainda representam um sério problema de saúde pública e acometem principalmente crianças dos países em desenvolvimento (WHO, 2009). Pacientes com gastroenterites são capazes de excretar entre $10^{9}$ a $10^{11}$ partículas virais por grama de fezes de indivíduos infectados, podendo manter-se infeccioso no ambiente e principalmente em águas residuais (STAGGEMEIER et al., 2015).

Outro agravante é a eliminação inadequada de resíduos de animais que torna o ambiente ainda mais impactado, além de afetar uma parcela significativa dos mesmos (BARARDI et al., 
2012). Dentre os vírus de animais que afetam a qualidade ambiental, merecem destaque o Adenovírus Porcino (PoAdV), Adenovírus Bovino (BAdV), Adenovírus Canino (CAV) e Adenovírus Aviário (AvAdV) (DALLA VECCHIA et al., 2015).

A circulação de partículas virais como HAdV-F ou HAdV-C poderá acarretar em infecções e doenças de agravos virais caso haja potencial infeccioso, tornando a população mais susceptível aos surtos, principalmente a qual reside próxima ao córrego. De maneira geral, o arroio tem sido utilizado como mera tubulação de esgotamento sanitário que deságua na BHRS (STAGGEMEIER et al., 2015; VECCHIA et al., 2012).

Apenas bactérias do Grupo coliformes totais e termotolerantes são utilizadas como indicadores de contaminação fecal e de acordo com os resultados encontrados, o CONAMA através da Resolução 357 de 2005, classifica os corpos de água doce nas condições e padrões de qualidade das águas em relação aos Coliformes termotolerantes para utilização humana (ASTRÖM et al., 2007; CARDUCCI et al., 2003; CONAMA, 2005). Vírus em análises microbiológicas de água como indicadores de contaminação somente em casos de surtos virais por veiculação hídrica, mas não é obrigatório tal fato (RODRIGUES et al., 2015).

O CONAMA 357/2005 também avalia e monitora os efeitos das atividades antrópicas no meio hídrico através da análise de parâmetros físico-químicos. A interferência do homem na geração de despejos domésticos ou residuais contribui para a introdução de compostos tanto orgânicos como inorgânicos na água, afetando a sua qualidade, a qual é resultante de fenômenos naturais e da atuação do homem (ALVES et al., 2008). Dentre os parâmetros físico-químicos, podemos citar o pH (potencial Hidrogeniônico), Condutividade, DBO (Demanda Bioquímica de Oxigênio), OD (Oxigênio Dissolvido) e Turbidez, conforme a metodologia padrão (BAIRD; CLESCERI, 2012).

A cafeína é proposta como marcador de dejetos humanos com a vantagem de ser onipresente e quase que inteiramente humana, devido ao fato de praticamente não estar em lançamentos agrícolas ou industriais. Algumas fontes vegetais naturais de cafeína existem, mas os níveis são geralmente insignificantes e podem, assim, ser desprezados (GARDINALI; ZHAO, 2002; PEELER et al., 2006; WU et al., 2008). Degradada lentamente no ambiente com uma meia-vida estimada entre 3 dias podendo ultrapassar 3 meses, é utilizada como um marcador de contaminação sanitária doméstica (BENOTTI; BROWNAWELL, 2009, SAUVÉ et al., 2012; SMITH, 2002).

O presente estudo visa avaliar a qualidade da água do Arroio Luiz Rau através da análise de bioindicadores de contaminação fecal como os agentes virais de origem humana (HAdV-F e HAdV-C) e animal (PoAdV, BAdV, CAV e AvAdV) e também bactérias do Grupo coliformes, além da avaliação de parâmetros físico-químicos (DBO, DQO, OD, pH) e da presença da cafeína, provenientes de pontos de concentração populacional urbana do município de Novo Hamburgo, bem como contribuir na identificação de contaminantes, os quais são lançados no Rio dos Sinos, principal fonte de abastecimento hídrico da região.

\section{METODOLOGIA}

Foram avaliados 2 pontos ao longo do Arroio Luiz Rau no mês de novembro de 2015, no município de Novo Hamburgo, de forma a demarcarem o início de intensa urbanização (P1), e como segundo ponto, uma área pós-intensa urbanização (P2), recebendo e carregando contaminantes e 
poluentes até a foz no Rio dos Sinos, principal fonte de captação da água para abastecimento público (Tabela 1).

Tabela 1 - Coordenadas Geográficas (Sirgas Datum 69) do Arroio Luiz Rau, afluente do Rio dos Sinos, RS, Brasil. P1 - Início de intensa urbanização / P2 - Pós-intensa urbanização

\begin{tabular}{ccc}
\hline PONTOS & COORDENADAS GEOGRÁFICAS \\
\hline P1 & S29 $40^{\prime} 13.4^{\prime \prime}$ & W05 $1^{\circ} 08^{\prime} 17.1^{\prime \prime}$ \\
P2 & $\mathrm{S}^{\circ} 9^{\circ} 43^{\prime} 05.9^{\prime \prime}$ & W051 $07^{\prime} 55.2^{\prime \prime}$ \\
\hline
\end{tabular}

Fonte: Elaborado pelos autores

Para análise de genoma viral, primeiramente as amostras de água foram concentradas utilizando o método de adsorção/eluição (KATAYAMA et al., 2002) e após, o DNA viral foi extraído utilizando o kit de extração Mini Spin Plus (Biopur®), conforme recomendações do fabricante. Em seguida, foi realizada a Reação em Cadeia da Polimerase em Tempo Real (qPCR). Foram utilizados os primers VTB1 para HAdVF (HAdVF-40 e HAdVF-41) e VTB2 para genoma do HAdVC (HAdVC-2 e HAdVC5) (WOLF et al., 2010). O genoma de AdV animal foi realizada como análise adicional - CAV, AvAdV, PoAdV e BAdV - foram usados primers ADV-R1 e ADV-F1 segundo Staggemeier et al. (2015). Essas análises foram realizadas no Laboratório de Microbiologia Molecular da Universidade Feevale.

Bactérias do grupo Coliformes totais e termotolerantes foram avaliadas de acordo com as indicações do Kit Colilert ${ }^{\circledR}$ (método enzimático) aprovado pelo Standard Methods for the Examination of Water and Wastewater, seguindo a metodologia do fabricante. Os parâmetros físico-químicos foram utilizados para avaliar a qualidade de água do local como $\mathrm{pH}$, condutividade, DBO, OD e turbidez de acordo com metodologia padrão (BAIRD; CLESCERI, 2012). Essas análises foram realizadas no Laboratório da Central Analítica da Universidade Feevale.

A análise de cafeína foi realizada através de Cromatografia Líquida de Alta Eficiência (HPLC) segundo método previamente descrito (LINDEN et al., 2015). O processamento e análise foram realizados nos Laboratórios de Toxicologia da Universidade Feevale.

\section{RESULTADOS}

Dentre os genomas virais analisados, foram detectados nos dois pontos de estudo os HAdV-F sorotipos 40/41 (gastroentérico); HAdV-C sorotipos 5/2 (respiratório) e CAV, com quantificações expressas conforme gráfico 1 .

Gráfico 1 - Quantificações Logarítmicas de AdV (cópias genômicas por litro de água) encontrados no Arroio LR, afluente do Rio dos Sinos. Ponto 1 (Início de intensa urbanização); Ponto 2 (Pós-intensa urbanização)

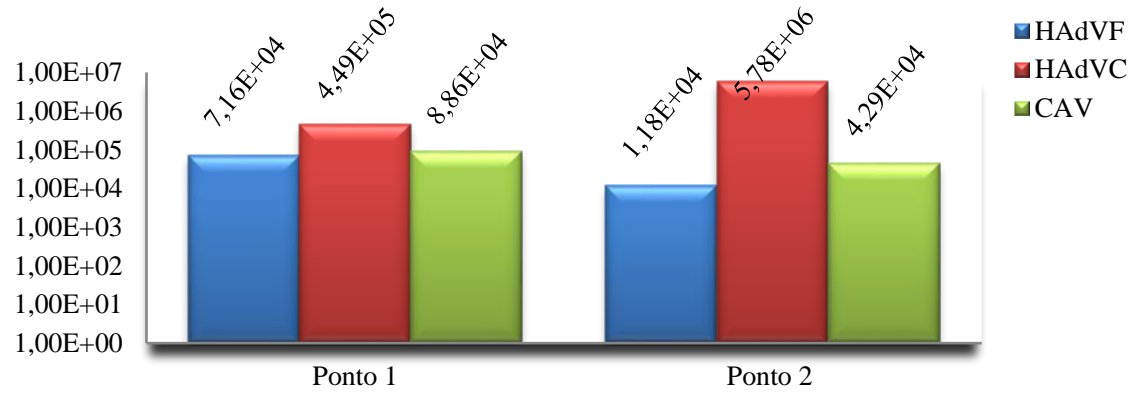

Fonte: Elaborado pelos autores 
Os resultados obtidos para as análises de Bactérias do grupo coliformes, parâmetros físico-químicos e cafeína estão registrados na tabela 2.

Tabela 2 -Análises Microbiológicas, Parâmetros físico-químicos e Cafeína.

\begin{tabular}{lcccccccc}
\hline & $\begin{array}{c}\text { Coliformes } \\
\text { Totais } \\
(\mathbf{N M P} / \mathbf{1 0 0} \mathbf{m L})\end{array}$ & $\begin{array}{c}\text { Coliformes } \\
\text { Termotolerantes } \\
(\mathbf{N M P} / \mathbf{1 0 0 m L})\end{array}$ & $\begin{array}{c}\text { DBO } \\
(\mathbf{m g O} / \mathbf{L})\end{array}$ & $\begin{array}{c}\text { OD } \\
(\mathbf{m g} / \mathbf{L})\end{array}$ & $\begin{array}{c}\text { Condutividade } \\
\left(\boldsymbol{\mu S} / \mathbf{c m}^{2}\right)\end{array}$ & $\begin{array}{c}\text { Turbidez } \\
(\mathbf{N T U})\end{array}$ & pH & Cafeína \\
\hline P1 & 1119900 & 260300 & 28 & 3 & 220 & 14,7 & 7,14 & 190,69 \\
$\mathbf{P 2}$ & 686700 & 290900 & 32 & 1,7 & 310 & 9,35 & 7,23 & 16,47 \\
\hline
\end{tabular}

P1 (Início de intensa urbanização); P2 (Pós- intensa urbanização).

Fonte: Elaborado pelos autores

\section{DISCUSSÃO}

O Arroio Luiz Rau, situado na porção baixa da BHRS, é o principal veículo carreador de esgotamento doméstico e de resíduos tornando-se de grande importância na disseminação de poluentes até o Rio dos Sinos (FIGUEIREDO et al., 2010; STRIEDER et al., 2006). Frequentemente águas residuais são lançadas nos recursos hídricos sem tratamento adequado, através de afluentes contaminando os mananciais de captação de água.

De forma geral, em comparação entre os pontos analisados, o P2 apresentou um aumento de poluentes de carga orgânica sugerindo o lançamento de matéria fecal de origem doméstica e industrial ao longo do córrego seguindo até a foz na BHRS. Os achados neste estudo estão associados ao fato do Arroio apresentar residências e indústrias com escoamento de águas residuais sem esgotamento sanitário adequado, que acabam disseminando os AdVs e afetando a qualidade do ambiente bem como colocando em risco a saúde do homem.

Os agentes virais mencionados acima são caracterizados pela sua estabilidade, tanto no aparelho gastrointestinal como no meio ambiente, bem como de serem excretados através das fezes de humanos e animais, além de resistir como contaminantes ambientais durante longos períodos de tempo (KATAYAMA et al., 2002). Vírus entéricos são frequentemente encontrados em águas superficiais, subterrâneas e residuais, são responsáveis por uma proporção significativa de casos de gastroenterites relacionados à água potável (ABBASZADEGAN et al., 1999; BORCHARDT et al., 2003).

HAdVs presentes nos pontos analisados são um dos principais agentes etiológicos de gastrenterites em crianças com idade inferior a 4 anos principalmente o HAdV-F sorotipos 40 e 41especificamente gastroentéricos (MEHNERT et al., 2001; FROST et al., 2002; LEE; KIM, 2002), com achados de $7,16 \times 10^{4}$ e $1,18 \times 10^{4}$ cópias genômicas por litro de água $(\mathrm{gc} / \mathrm{L})$ nos pontos 1 e 2 , respectivamente, o que demonstra a presença de contaminantes fecais humanos. Este patógeno está incluído na "Contaminant Candidate List 4" da Agência de Proteção Ambiental Americana (USEPA) por sua importância sanitária e sua elevada incidência em amostras de água e esgoto (STAGGEMEIER et al., 2015).

Em relação aos HAdV-C sorotipos 2 e 5, foram detectados maiores quantificações $\left(4,49 \times 10^{5}\right.$ no $\mathrm{P} 1$ e $5,78 \times 10^{6} \mathrm{gc} / \mathrm{L}$ no P2), em comparação com os outros AdV investigados nos pontos analisados do córrego, pois apesar de serem respiratórios, são os agentes virais geralmente mais excretados através das fezes por humanos, e desta maneira, a presença de tal patógeno indica contaminação fecal humana (FONGARO et al., 2013; MENA; GERBA, 2009). 
Além de gastroenterites e infecções respiratórias, tais sorotipos são capazes de causar também cardiopatias, particularmente em crianças e neonatos (SILVA et al., 2015). Estes diferentes tipos de HAdV, sugerem a falta ou deficiência de um tratamento adequado do esgoto doméstico e possíveis riscos à saúde humana. Em uma pesquisa realizada por Vecchia et al., (2012) no Arroio Dilúvio da cidade de Porto Alegre foram detectados HAdV (21,43\%), este arroio recebe esgoto sanitário da população e tem sua foz no Lago Guaíba que é um manancial de abastecimento de água desta mesma cidade.

Em outro estudo em águas do Rio dos Sinos, em pontos de captação para abastecimento, realizado por Dalla Vecchia et al., (2015), foi identificado HAdV-C com quantificação viral de variação de $10^{2}-10^{4} \mathrm{gc} / \mathrm{L}(62,5 \%)$ de água coletadas em pontos de captação, valor semelhante aos detectados nestes 2 pontos de análise do Arroio do presente estudo, e atuando como veículo de transporte de partículas virais até o Rio dos Sinos, justificando a necessidade de implantação de infraestrutura sanitária adequada.

Estudos relacionados à qualidade do ambiente, demonstraram que, assim como os HAdV, AdV animais também são considerados bons marcadores de contaminação fecal no devido a sua alta prevalência (STAGGEMEIER et al., 2015). Segundo este mesmo autor, um estudo em propriedades rurais na região do Vale do Paranhana, pertencente a BHRS, foram analisadas águas de diferentes locais obtendo uma detecção de 87,3\% de HAdV-C (48/55); 27,3\% de AvAdV (15/55); 20\% de CAV (11/55); $7,3 \%$ de BAV (4/55) e 1,8\% de PoAdV.

Dentre os vírus pesquisados neste estudo que infectam os animais, encontramos valores positivos

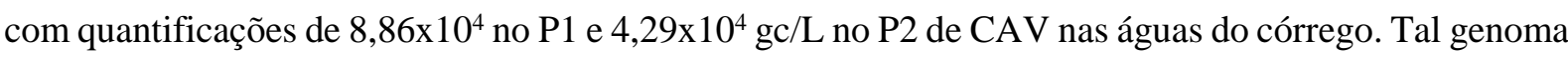
viral oriundo de cães é considerado como indicador de contaminação fecal no ambiente, a presença de tal agente viral demonstra que o arroio também recebe resíduos fecais animais possivelmente provenientes de esgoto pluvial que acaba por trazer águas que passaram por rua e que podem ter trazido consigo as fezes de animais de rua, além disso, algumas pessoas tem o costume de jogarem as fezes de seus pets no vaso sanitário. No Rio Grande do Sul, Dezengrini et al. (2007) demonstraram a circulação desse vírus entre os cães através de pesquisa com 817 cachorros no período entre 2004 e 2005, obtendo positividade de $43 \%$ (353/817).

Em relação às análises de Coliformes Totais e Termotolerantes, o P1 apresentou 1119900 $\mathrm{NMP} / 100 \mathrm{~mL}$ de água de coliformes totais, bactérias que habitam o trato intestinal podendo ser de seres humanos e animais e em relação aos termotolerantes, que indicam contaminação fecal humana, foi encontrado $260300 \mathrm{NMP} / 100 \mathrm{~mL}$ de água, o que demonstra uma grande contaminação de dejetos fecais humanos neste local onde inicia o aumento populacional.

Por sua vez, o P2, apresentou $686700 \mathrm{NMP} / 100 \mathrm{~mL}$ (coliformes totais) e $290900 \mathrm{NMP} / 100 \mathrm{~mL}$ (coliformes termotolerantes), apresentando um aumento de bactérias do trato intestinal humano maior no P2 em relação ao P1. Assim, em comparação aos pontos de coleta, há um aumento crescente do P1 ao P2 em contaminação antrópica com valores consideráveis, mesmo sabendo-se que muitos dos dejetos e poluentes podem permanecer nas margens e no solo, ficando expostos ao ambiente. A presença de bactérias do Grupo Coliformes, incluindo coliformes termotolerantes sugerem que a água está contaminada com matéria fecal (KURISSERY et al., 2012). O percurso do córrego entre os P1 e P2 passa por todo o centro de Novo Hamburgo, local de intensa urbanização, havendo durante esse trajeto o lançamento de esgotos provenientes de residências e indústrias, além de possuir o arroio Guarani como afluente, o que justificaria o maior valor de coliformes fecais no P2. 
Em contrapartida, os valores de cafeína obtidos foram de maiores quantificações no P1. Um estudo em Portugal, também indicou valores maiores de cafeína em áreas urbanas (SILVA et al., 2014), confirmando assim a vantagem de ser um bom marcador de dejetos humanos e de não estar presente em lançamentos agrícolas ou industriais (PEELER et al., 2006; LINDEN et al., 2015), uma vez que este local possui maior concentração de áreas residenciais.

Desta forma, este curso d'água, apesar de apresentar canalização em parte de seu trajeto, encontrase exposto em céu aberto no P1 e no P2, locais onde foram obtidas as amostras de água do arroio para a análise. O córrego do presente estudo passa por bairros populacionais ao longo de seu trajeto, sendo receptor de todo esgoto doméstico e de poluentes industriais de pequeno e médio porte.

Segundo Robaina et al. (2002), o Arroio Luiz Rau é considerado um dos córregos mais impactados na BHRS e para Nascimento (2007) a escassez de água com o constante crescimento populacional ocasiona no aumento da poluição doméstica ou industrial e assim determinam a necessidade de uso racional das águas, propondo medidas que auxiliem na melhoria dos mananciais hídricos superficiais, bem como o tratamento de esgoto sanitário.

Podemos observar nos parâmetros físico-químicos que houve coerência nos resultados analisados nos valores de DBO, OD e condutividade, pois no $\mathrm{P} 2$ encontramos maior número de Bactérias Termotolerantes, principal marcador de contaminação fecal humana, e maiores valores de DBO e condutividade, e menor valor de OD em relação ao P1. Tais bactérias utilizam o oxigênio dissolvido na água, o que acarreta em menor valor de OD onde foi encontrada a quantidade maior de Coliformes Termotolerantes (P2). Em relação ao aumento na DBO, este parâmetro está relacionado diretamente com a quantidade de matéria orgânica, logo, temos uma diminuição de OD e aumento de DBO, demonstrando assim maior concentração de coliformes fecais e maior quantidade de matéria orgânica no P2. No parâmetro da condutividade, o P2 demonstrou também maior valor em relação ao P1 devido a maior quantidade na concentração de íons, podendo estar relacionada a quantidades maiores de poluentes industriais da região.

Em relação a turbidez e ao pH da água, não houve correlação nos pontos analisados, levando em consideração períodos extremamente chuvosos em dias consecutivos que antecederam a coleta de amostragem, fator de grande influência a ser considerado em tais parâmetros podendo influenciar nos resultados obtidos.

A gestão adequada dos recursos hídricos é imprescindível em decorrência da extensa urbanização e escassez de água, de tal modo que o mais adequado é o monitoramento ambiental integrado, gestão e planejamento para tomadas de decisões que possam amenizar impactos ambientais causados pela ocupação populacional e pela industrialização (NAIME; FAGUNDES, 2005).

Atualmente, o Arroio Luiz Rau é usado como córrego para despejo de esgotos domésticos e industriais, o monitoramento nestes dois pontos, de início (P1) e fim (P2) de crescimento populacional, é capaz de demonstrar o impacto gerado pela falta de saneamento básico ou ineficácia de esgotamento sanitário, alcançando o Rio dos Sinos (PRADO; MIAGOSTOVICH, 2014). Logo, este fato contribui para agravar os níveis de contaminantes e a disseminação viral no ambiente, colocando em risco a saúde da população.

Strieder e colaboradores em 2006 já relatavam que a significativa poluição do Rio dos Sinos tinha origem em pequenos afluentes, e Dalla Vecchia et al. (2015) mostraram que o grande problema da BHRS é o esgoto doméstico, o que esse estudo vem a confirmar essas questões e apesar de ser determinado pela legislação ambiental vigente, o monitoramento das águas superficiais não é prioridade, sendo muitas vezes realizado apenas de forma esporádica. Excluindo-se os rios principais das bacias 
hidrográficas, são poucos os arroios da região metropolitana de Porto Alegre que foram alvo de algum tipo de monitoramento físico-químico e microbiológico (NASCIMENTO, 2007).

\section{CONCLUSÃO}

O Arroio Luiz Rau é um veículo na disseminação de efluentes sem tratamento adequado, tanto doméstico quanto industrial sendo receptor de esgoto sem tratamento sanitário. A presença do genoma dos HAdV e CAV demonstram o impacto antrópico e ambiental bem como a disseminação viral, agravando as condições do ambiente.

Conforme os parâmetros microbiológicos e físico-químicos, torna-se evidente também o impacto antrópico confirmado por mais estes parâmetros. E por fim, a cafeína encontrada em maiores valores no início do aumento populacional do Arroio LR, que atua como marcador eficaz de contaminação antrópica, mesmo não estando presente na Legislação, vem a acrescentar mais uma forma de avaliar a qualidade da água e de efluentes que acabam por ser lançados no Rio dos Sinos, principal fonte e abastecimento para a população.

Tais análises contribuem de forma pontual e têm como maior importância corroborar com a geração de dados para uma melhor construção de gestão e planejamento de esgotamento sanitário, visando a saúde da população e o meio ambiente, uma vez que a qualidade deste reflete diretamente na saúde pública. Investindo-se em saneamento, os recursos ambientais tornam-se menos degradados, o que reflete na qualidade de vida humana diminuindo os riscos e gastos com a saúde pública.

\section{REFERÊNCIAS}

ABBASZADEGAN, M.; STEWART, P.; LECHEVALLIER, M.A. Strategy for detection of viruses in groundwater by PCR. Applied and Environmental Microbiology, v. 65, p. 444-449, 1999.

ALVES, E.C.; SILVA, C.F.; COSSICH, E.S.; TAVARES, C.R.G.; FILHO, E.E.S.; CARNIEL, A. Avaliação da qualidade da água da bacia do Rio Pirapó - Maringá, Estado do Paraná, por meio de parâmetros físicos, químicos e microbiológicos. Acta Scientiarum Technology, v. 30, n. 1, p. 39-48, 2008.

ANA - Agência Nacional de Águas. Conjuntura dos Recursos Hídricos do Brasil. Disponível em: <http://www3.snirh.gov.br/portal/snirh/centrais-de-conteudos/conjuntura-dos-recursoshidricos/conj2013_rel.pdf >. Acesso em: 15 abr. 2017.

ASTRÖM, J.; PETTERSSON, T.J.; STENSTRÖM, T.A. Identification and management of microbial contaminations in a surface drinking water source. Journal of Water and Health, v. 5(Suppl 1), p. 67-79, 2007.

ÁVILA, C.L.A. Preliminar de Metais Pesados Totais e Biodisponíveis em Profundidade no Sedimento do Arroio Luíz Rau em Novo Hamburgo (RS). 2011. 74p. Trabalho de Conclusão ("Bacharel em Engenharia Industrial Química"). Universidade Feevale, Novo Hamburgo, Rio Grande do Sul, 2011.

BAIRD, R. B.; CLESCERI, L.S. Standard methods for examination of water and wastewater American Public Health Association. Estados Unidos da América: Amer Public Health, 22 ed., 2012. $1496 \mathrm{p}$. 
BARARDI, C.R.M.; VIANCELLI, A.; RIGOTTO, C.; CORREAA, A.A.; MORESCO, V.; SOUZA, D.S.M.; ELMAHDY, M.E.I.; FONGARO, G.; PILOTTO, M.R.; NASCIMENTO, M.A. Monitoring viruses in environmental samples. International Journal of Environmental Science and Engineering Research, v. 3, n. 3, p. 62-79, 2012.

BENOTTI, M.J.; BROWNAWELL, B.J. Microbial degradation of pharmaceuticals in estuarine and coastal seawater. Environmental Pollution, v. 157, p. 994-1002, 2009.

BLUME, K.K.; MACEDO, J.C.; MENEGUZZI, A.;SILVA, L.B.; QUEVEDO, D.M.; RODRIGUES, M.A.S. Water quality assessment of the Sinos River, Southern Brazil. Brazilian Journal of Biology, v. 70, p. 1185-1193, 2010.

BORCHARDT, M.A.; BERTZ, P.D.; SPENCER, S.K.; BATTIGELLI, D.A. Incidence of enteric viruses in groundwater from household wells in Wisconsin. Applied and Environmental Microbiology, v. 69, p. 1172-1180, 2003.

CARDUCCI, A.; CASINI, B.; BANI, A.; ROVINI, E.; VERANI, M.; MAZZONI, F.; GIUNTINI, A. Virological control of groundwater quality using biomolecular tests. Water Science and Technology, v. 47 , p. $261-266,2003$.

CONAMA. Ministério do Meio Ambiente. Conselho Nacional de Meio Ambiente. Resolução no 357, de 17 de Março de 2005. Dispõe sobre a classificação dos corpos de água e diretrizes ambientais para o seu enquadramento, bem como estabelece as condições e padrões de lançamento de efluentes, e dá outras providências. Diário Oficial, 18 de março de 2005. Disponível em:

<http://www.mma.gov.br/port/conama/res/res05/res35705.pdf>. Acesso em: 05 nov. 2016.

DALLA VECCHIA, A.; RIGOTTO, C.; STAGGEMEIER, R.; SOLIMAN, M.C.; GIL DE SOUZA, F.; HENZEL, A.; SANTOS, E.L.; DO NASCIMENTO, C.A.; DE QUEVEDO, D.M.; FLECK, J.D.; HEINZELMANN, L.S.; DE MATOS ALMEIDA, S.E.; SPILKI, F.R. Surface water quality in the Sinos River basin, in Southern Brazil: tracking microbiological contamination and correlation with physicochemical parameters. Environmental Science and Pollution Research, v. 22, n. 13, p. 98999911, 2015.

DASHTI, A.S.; GRAHREHMANI, P.; HASHEMPOOR, T.; KARIMI, A. Molecular Epidemiology of Enteric Adenovirus Gastroenteritis in under-Five-Year-Old Children in Iran. Gastroenterology Research and Practice, v. 2016, p. 1-5, 2016.

DEZENGRINI, R.; WEIBLEN, R.; FLORES, E.F. Soroprevalência das infecções por parvovírus, adenovírus, coronavírus canino e pelo vírus da cinomose em cães de Santa Maria, Rio Grande do Sul, Brasil. Ciência Rural, v. 37, n. 1, p. 183-189, 2007.

FIGUEIREDO, J.A.S.; DRUMM, E.; RODRIGUES, M.A.S.; SPILKI, F.R. The Rio dos Sinos watershed: an economic and social space and its interface with environmental status.

BrazilianJournalofBiology, v. 70, n. 4, p. 1131-1136, 2010.

FONGARO, G.; NASCIMENTO, M.A.; RIGOTTO, C.; RITTERBUSCH, G.; DA SILVA, A.D.A.; ESTEVES, P.A.; BARARDI, C.R.M. Evaluation and molecular characterization of human adenovirus in drinking water supplies: viral integrity and viability assays. Virology Journal, v. 10, p. 166, 2013.

FROST, F.J.; KUNDE, T.R.; CRAUN, G.F. Is contaminated groundwater an important cause of viral gastroenteritis in the United States? Journal of Environmental Health, v. 65, p. 9-14, 2002.

GARDINALI, P.R.; ZHAO, X. Trace determination of caffeine in surface water samples by liquid chromatography-atmospheric pressure chemical ionization-mass spectrometry (LC-APCI-MS).

Environment International, v. 28, p. 521-528, 2002. 
IBGE. Instituto Brasileiro de Geografia e Estatísticas. 2010. Disponível em: $<$ http://cidades.ibge.gov.br/xtras/perfil.php?lang=\&codmun=431340\&search=||infogr\%E1ficos:informa\%E7\%F5es-completas>. Acesso em: 05 dez. 2016.

KATAYAMA, H.; SHIMASAKI, A.; OHGAKI, S. Development of a Virus Concentration Method and Its Application to Detection of Enterovirus and Norwalk Virus from Coastal Seawater. Applied and Environmental Microbiology, v. 68, p. 1033-1039, 2002.

KURISSERY, S.; KANAVILLIL, N.; VERENITCH, S.; MAZUMDER, A. Caffeine as an anthropogenic marker of domestic waste: A study from Lake Simcoe watershed. Ecological Indicators, v. 23, p. 501-508, 2012.

LEE, S.H.; KIM, S.J. Detection of infectious enteroviruses and adenoviruses in tap water in urban areas in Korea. Water Research, v. 36, p. 248-256, 2002.

LINDEN, R.; ANTUNES, M.V.; HEINZELMANN, L.S.; FLECK, J.D.; STAGGEMEIER, R.; FABRES, R.B.; VECCHIA, A.D.; NASCIMENTO, C.A.; SPILKI, F.R. Caffeine as an indicator of human fecal contamination in the Sinos River: a preliminary study. Brazilian Journal of Biology, v. 75, p. S81-S84, 2015.

MATSUSHIMA, Y.; SCHIMIZU, H.; KANO, A.; NAKAJIMA, E.; ISHIMARU, Y.; DEY, S.K.; WATANABE, Y.; ADACHI, F.; MITANI, K.; FUJIMOTO, T.; PHAN, T.G.; USHIJIMA, H. Genome Sequence of a Novel Virus of the Species Human Adenovirus D Associated with Acute Gastroenteritis. Genome Announcements, v. 1, p. 1-2, 2013.

MEHNERT, D.U.; QUEIROZ, A.P.S.; PAULI, V.; MONEZI, T.A.; HÁRSI, C. M. Virus: a new parameter for determination of water quality. Virus Reviews \&Research, v. 6, p. 67, 2001.

MENA, K.D; GERBA, C.P. Waterborne Adenovirus. Reviews of Environmental Contamination and Toxicology, v. 198, p. 133-167, 2009.

NAIME, R.; FAGUNDES, R.S. Controle da Qualidade da Água do Arroio Portão Portão, RS. Pesquisas em Geociências, v. 32, n. 1, p. 27-35, 2005.

NASCIMENTO, C. A. Arroio Pampa: Condição Atual e Sua Contribuição para as Águas do Rio dos Sinos, Rio Grande do Sul. 2007. 108p. Dissertação (Mestrado em "Qualidade Ambiental") Universidade Feevale, Novo Hamburgo, Rio Grande do Sul, 2007.

PEELER, K.A.; OPSHAL, S.P.; CHANTON, J.P. Tracking anthropogenic inputs using caffeine, indicator bacteria, and nutrients in rural freshwater and urban marine systems. Environmental Science and Technology, v. 40, p. 7616-7622, 2006.

PRADO, T.; MIAGOSTOVICH, M.A. Virologia ambiental e saneamento no Brasil: uma revisão narrativa. Caderno de Saúde Pública, v. 30, n. 7, p. 1367-1378, 2014.

PREFEITURA DE NOVO HAMBURGO, 2015. Dados Gerais. Disponível em: <http://novohamburgo.org/site/nossa-cidade/dados-gerais>. Acesso em: 20 nov. 2016.

ROBAINA, L.E.; FORMOSO, M.L.L.; PIRES, C.A. F. Metais pesados nos sedimentos de corrente, como indicadores de risco ambiental - Vale do Rio dos Sinos, RS. Revista do Instituto Geológico, p. 23, n. 2, p. 35-47, 2002.

RODRIGUES, M.; HENZEL, A.; STAGGEMEIER, R.; QUEVEDO, D.M.; RIGOTTO, C.; HEINZELMANN, L.; NASCIMENTO, C.A.; SPILKI, F.R. Human adenovirus spread, rainfalls, and the occurrence of gastroenteritis cases in a Brasilian basin. Environmental Monitoring and Assessment, v. 187, p. 720, 2015. 
SAUVÉ, S.; ABOULFADL, K.; DORNER, S.; PAYMENT, P.; DESCHAMPS, G.; PRÉVOST, M. Fecal coliforms, caffeine and carbamazepine in storm water collection systems in a large urban area. Chemosphere, v. 86,p. 118-123, 2012.

SILVA, C.P.; LIMA, D.L.; SCHNEIDER, R.J.; OTERO, M.; ESTEVES, V. I. Evaluation of the anthropogenic input of caffeine in surface waters of the north and center of Portugal by ELISA. Science of the Total Environment, v. 479-480, p. 227-232, 2014.

SILVA, H.D.; FONGARO, G.; GARCÍAZAPATA, M.T.A.; MELO, A.T.O.; SILVEIRA-LACERDA, E.P.; DE FARIA, K.M.S.; ANUNCIAÇÃO, C.E. High Species C Human Adenovirus Genome Copy Numbers in the Treated Water Supply of a Neotropical Area of the Central-West Region of Brazil. Food and Environmental Virology, v. 7, n. 3, p. 286-294, 2015.

SMITH, A. Effects of caffeine on human behavior. Food and Chemical Toxicology, v. 40, p. 1243$1255,2002$.

STAGGEMEIER, R. Vírus Entéricos Humanos em Sedimento e Água Superficial de Áreas Urbanas da Região do Vale do Rio dos Sinos, RS. 2016. 71p. Tese (Doutorado em "Qualidade Ambiental") - Universidade Feevale, Novo Hamburgo, Rio Grande do Sul, 2016.

STAGGEMEIER, R.; BORTOLUZZI, M.; HECK, T.M.S.; LUZ, R.; FABRES, R.; SOLIMAN, M.; RIGOTTO, C.; BALDASSO, N.; SPILKI, F.; ALMEIDA, S. Animal and human enteric viruses in water and sediment samples from dairy farms. Agricultural Water Management, v. 152, p. 135-141, 2015.

STEFFENS, C.; KLAUCK, C.R.; BENVENUTI, T.; SILVA, L.B.; RODRIGUES, M.A.S. Water quality assessment of the Sinos River - RS, Brazil. Brazilian Journal of Biology, v. 75, p. S62-S67, 2015.

STRIEDER, M.N.; RONCHI, L. H.; STENERT, C.; SCHERER, R. T.; NEISS, U. G. Medidas Biológicas e Índices de Qualidade da Água de uma Microbacia com Poluição Urbana e de Curtumes no Sul do Brasil, RS. Acta Biologica Leopondensia, v. 28, p. 17-24, 2006.

VECCHIA, A.D.; FLECK, J.D.; COMERLATO, J.; KLUGE, M.; BERGAMASCHI, B.; SILVA, J.V.S.; LUZ, R.B.; TEIXEIRA, T.F.; GARBINATO, G.N.; OLIVEIRA, D.V.; ZANIN, J.G.; SAND, S.V.D.; FRANCO, A.C.; ROEHE, P.M.; SPILKI, F.R. First description of Adenovirus, Enterovirus, Rotavirus and Torque teno virus on water samples collected from the Arroio Dilúvio, Porto Alegre, Brazil. Brazilian Journal of Biology, v. 72, n. 2, p. 323-329, 2012.

VELLINGA, J.; VAN DEN WOLLENBERG, D.J.M.; VAN DER HEIJDT, S.; RABELINK, M.J.W.E.; HOEBEN, R.C. The coiled-coil domain of the adenovirus type 5 protein IX is dispensable for capsid incorporation and thermostability. Journal of Virology, v. 79, p. 3206-3210, 2005.

VIEIRA, C.B.; MENDES, A.C.O.; GUIMARÃES, F.R.; FUMIAN, T.M.; LEITE, J.P.G.; GASPAR, A.M.C.; MIAGOSTOVICH, M.P.Detection of enteric viruses in recreational waters of an urban lagoon in the city of Rio de Janeiro, Brazil. Memórias do Instituto Oswaldo Cruz, v.107, n. 6, p. 778-784, 2012.

WOLF, S.; HEWITT, J.; GREENING, G.E. Viral multiplex quantitative PCR assays for tracking sources of fecal contamination. Applied and Environmental Microbiology, v. 76, p. 1388-1394, 2010. 
WORLD HEALTH ORGANIZATION (WHO). Diarrhea: why children are still dying and what can be done. 2009. Disponível em:

<http://apps.who.int/iris/bitstream/10665/44174/1/9789241598415_eng.pdf>. Acesso em: 15 abr. 2017.

WU, J.; YUE, J.; HU, R.; YANG, Z.; ZHANG, L. Use of caffeine and human pharmaceuticals compounds to identify sewage contamination. International Journal of Medical, Health, Biomedical, Bioengineering and Pharmaceutical Engineering, v. 2, p. 289-293, 2008.

WYN-JONES, A.P.; CARDUCCI, A.; COOK, N.; D'AGOSTINO, M.; DIVIZIA, M.; FLEISCHER, J.; GANTZER, C.; GAWLER, A.; GIRONES, R.; HÖLLER, C.; DE RODAHUSMAN, A.M.; KAY, D.; KOZYRA, I.; LÓPEZ-PILA, J.; MUSCILLO, M.; NASCIMENTO, M.S.; PAPAGEORGIOU, G.; RUTJES, S.; SELLWOOD, J.; SZEWZYK, R.; WYER, M. Surveillance of adenoviruses and noroviruses in European recreational waters. Water Research, v. 45, p. 1025-1038, 2011. 